\title{
Usability of Wireless ECG Body Sensor for Cardiac Function Monitoring During Field Testing
}

\author{
Boris Širaiy ${ }^{1}$, Vladimir Ilić ${ }^{1}$, Lazar Toskić ${ }^{2,3}$ \\ ${ }^{1}$ Faculty of Sport and Physical Education, University of Belgrade, Blagoja Parovića 156, 11000 Belgrade, Serbia, \\ boris.siraiy@hotmail.com \\ ${ }^{2}$ Faculty of Sport and Physical Education, University in Priština - Kosovska Mitrovica, Dositeja Obradovića bb, 38218 \\ Leposavić, Serbia \\ ${ }^{3}$ Faculty of Sport, University ' 'Union - Nikola Tesla', Narodnih heroja 30/l, 11000 Belgrade, Serbia
}

\begin{abstract}
Wireless ECG body sensor Savvy is a feasible solution for reliable and accurate long-term heart rhythm monitoring. However, there were no studies dealing with usability of this sensor in field testing. Accordingly, the aim of the study is to evaluate the quality of the ECG signal measured with wearable wireless ECG body sensor when used in field test settings and to determine how different types of sensor fixation affects the quality of the ECG signal during sub-maximal and maximal running settings. Twenty-three participants, 10 females and 13 males, were included in the study (20.56 \pm 1.19 years). All subjects performed shuttle run (SR), Cooper $2400 \mathrm{~m}$ (C), and $100 \mathrm{~m}$ sprint test (S), once wearing the sensor attached to self-adhesive skin electrodes, additionally fixed with self-adhesive tapes, and secondly with the sensor attached to Polar belt and strapped around the chest. Test outcomes were compared applying the Student t-test for dependent variables, or the non-parametric Wilcoxon test, depending on the results of the normality test. The results showed a significant difference $(p<0.05)$ in the running speed that provides an assessable ECG signal between two different types of fixation in all three running tests - C, S, SR, as well as between the parameters "QRS detected as negative", "correct software detection", and "detected QRS" in the C and SR tests. Findings obtained in this study proved that if properly fixed, the ECG signal recorded with wireless ECG can be efficiently used for heart monitoring during physical activities in real setting and potentially could be used as additional tool in detection of cardiovascular diseases. In addition, fixation with Polar belt is more adequate for measurements made during physical activity in real setting compared to fixation with tape.
\end{abstract}

Keywords: Telemetry, exercise testing, prevention, ECG, field tests.

\section{INTRODUCTION}

Today's lifestyle presents a high risk for cardiovascular diseases, which is a leading cause of death worldwide [1]. Previous studies have targeted various risk factors for development of cardiovascular diseases, such as high blood pressure, smoking, type 2 diabetes, obesity, psychological stress, and physical inactivity [1], [2].

Increased level of physical activity has numerous beneficial long-term effects on the cardiovascular system, and might decrease the relative risk of sudden cardiac death [3]. However, the risk of unexpected cardiovascular event is increased during, and immediately after intense exercise [4], [5]. Two studies conducted in France reported a daily incidence of three sudden deaths and four myocardial infarctions during regular physical activity in the general population [6], [7]. A twelve-year longitudinal study showed that average age of young recreational athletes in Switzerland who died during physical activity was 27.6 years, with the incidence of $0.52 / 100.000$ per year [8]. Chevalier et al. [6] reported dramatic increase of unexpected cardiovascular events in a middle age group of recreational population, which was at the level of 6.5/100.000 per year. Furthermore, several studies reported higher incidence of sports related cardiovascular events among the general population in comparison with professional athletes [6], [9], [10]. Males are more affected, and the most affected age group is middleaged between 35 and 59 years [11].

Goodman et al. [11] noticed that the key challenge is identification of structural heart disease and inheritable conditions that increase incidence for lethal arrhythmias during exercise, because sudden cardiac events often occur without any warning or prediction. Therefore, early detection of persons with higher risk for sudden cardiac death is of crucial importance [12]. In this regard, numerous European countries have introduced a mandatory medical examination for all persons registered in sports clubs or associations. Exercise stress test (EST) which includes electrocardiographic (ECG) monitoring is an important part of examination [5], [13], [14]. However, the problem arises from the fact that EST is especially sensitive for testing 
individuals with previously known symptoms of cardiac disease, while the positive predictive value of an EST in asymptomatic subjects is relatively low [6], [15]. On the other hand, it was proven that long term ECG monitoring during regular daily activities can be very useful in the detection of heart disease in people who had normal 12-lead ECG, and negative Master two-step tests [16]. Furthermore, it was proven that it is possible to detect atrial fibrillation in asymptomatic people with long-term one-channel ECG monitoring [17].

Recent studies showed that the wireless body ECG sensor is a feasible solution for reliable and accurate long-term heart rhythm monitoring, but the sensor placement and fixation is an important factor which can influence the signal quality and needs to be taken into consideration [18], [19], [20]. Accordingly, our main goal was to define whether it is possible to measure quality electrocardiographic report using an ECG body-sensor during standardized outdoor tests. Additional aim was to determine whether different types of sensor fixation affect quality of the ECG signal during submaximal and maximal running settings.

\section{SUBJECT \& METHODS}

\section{A. Study population}

Twenty-three participants were included in the study with 13 males (Age $=21.54 \pm 1.07$ years; Body height = $183.22 \pm 5.29 \mathrm{~cm} ;$ Body mass $=78.62 \pm 4.73 \mathrm{~kg}$ ) and 10 females $($ Age $=19.62 \pm 0.84$ years; Body height $=$ $171.34 \pm 8.24 \mathrm{~cm} ; \quad$ Body mass $=61.60 \pm 5.73 \mathrm{~kg}$ ). All participants were physically active non-athletes, with daily involvement (3-5 times per week, 30 to 60 minutes of moderate to high intensity) in various physical activities (team sports, cyclic activities, resistance training). Two male participants were smokers (less than 5 cigarettes a day), while 5 participants (4 males and 1 female) were reported to occasionally consume moderate amounts of alcoholic beverages. To meet the criteria for participation in the study, participants had to confirm they were healthy (no musculoskeletal and connective tissue disorders or illness that would influence testing result), and without known previous cardiac problems. The sample of participants was limited to healthy young adults for the reasons of physical activity intensity in the applied tests. In accordance with the Declaration of Helsinki participants gave the signed consent for participation in the study. Prior to the tests, the purpose and protocols of the study were explained in details to each participant. Ethics approval for the study was obtained from the Institutional Ethical committee (Approval No.02$1359 / 18-2)$. The study is registered at ClinicalTrials.gov (ID number NCT04786509).

\section{B. ECG signal monitoring}

Wireless ECG body sensor Savvy (Saving d.o.o., Ljubljana, Slovenia), which is a certified medical device, was used for collecting ECG data [21]. The body sensor allows ECG measurements during long-term exercise, with a sampling rate between $125 \mathrm{~Hz}$ and $1000 \mathrm{~Hz}$. An Android application, MobECG 1.8.8.3., which runs on a smartphone (LG K10), connected to the sensor via Bluetooth, captures and displays the measured data and saves it in the smartphone memory for further processing.

The optimal placement for the electrodes was close to the heart in order to obtain the appropriate amplitude of the ECG signal. Considering that the signals from the electrical muscular activity (EMG) could disturb the ECG signal, especially during physical activity, sensor position was placed to avoid large muscle groups [22]. In this study, we tested the position marked as left inferior (LI). At the LI position electrodes were placed at the positions of standard anterior precordial leads V1 and V2, and then the sensor was translated downward by approximately $10 \mathrm{~cm}$ (below the xiphoid), where the influence of muscular disturbances is expected to be minimal [19], [23], [24].

In the first test standard self-adhesive Skintact ECG electrodes type PREMIER T-60 were used (Leonhard Lang $\mathrm{GmbH}$, Innsbruck, Austria). The electrodes were in the original packaging and used according to the manufacturer's instructions. The ECG electrodes were positioned $5 \mathrm{~cm}$ apart [24]. Before the positioning, the skin of the subjects was cleaned with diluted ethanol. Then, two electrodes were stuck at the LI position, and the ECG body-sensor was connected. The sensor was additionally fixed with self-adhesive Omniplast $2.5 \mathrm{~cm}$ tape (Paul Hartmann AG, Heidenheim, Germany), specially designed to fix Holter electrodes (see Fig.1.) [19]. Both parts of the sensor were fixed together with one, approximately 40-cm-long strip of tape. In the second measurement Polar soft strap belt (Polar Electro Oy, Finland) was used to connect the sensor (see Fig.1.).
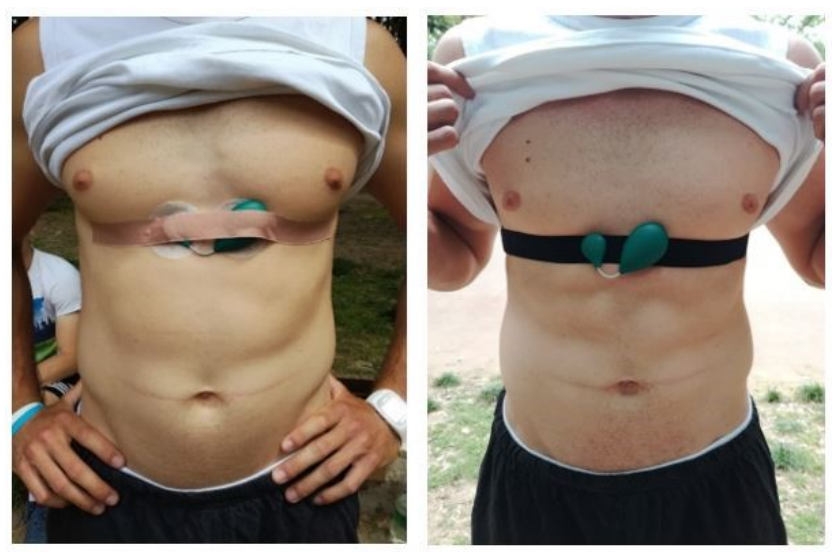

Fig.1. LI position of the sensor and electrodes fixed with tape in the first test (left) and in the second test (right), where sensor was fixed with Polar soft-strap belt.

The measured ECG data were continuously stored in the smartphone memory and transferred after the completion of the measurements to a personal computer. All the ECG measurements were analysed retrospectively. The subsequent ECG analyses and signal quality were made with medically certified Holter interpretation software QuickReader ${ }^{\circledR}$ AFT1000 (Holter Supplies, Paris, France). Moreover, all the measurements and the results were visually examined by a medical doctor. Only signals where QRS waves were clear and recognized without doubt where marked as useful. 
Variables used in the study were: Detected QRS, QRS detected as negative (\%), False negative detection (\%), Correct software detection (\%), Load / speed with still assessable HR (\%), Maximal HR [bpm], Average running time (s) (for Cooper 2400 and $100 \mathrm{~m}$ tests) and Average achieved intensity (for shuttle run). False negative detection represents QRS waves that the software has mistakenly recognized as illegible. When the signal was visually examined (by the medical doctor), it was determined that those signals were still satisfactory. Correct software detection represents a part of the signal that was recognized as illegible by the software. When the signal was visually inspected, it was determined that that part of the signal was really illegible and unusable.

\section{Test protocols}

In this study we used three different standardized running tests, one sub-maximal test - Cooper $2400 \mathrm{~m}$ (C), and two maximal (all-out) tests $-100 \mathrm{~m}$ sprint (S) and shuttle run (SR). In the C test participants had to run $2400 \mathrm{~m}$ [25], while in the $\mathrm{S}$ test they had to run $100 \mathrm{~m}$ from four point starting position at the highest possible speed. In the SR test standard test protocol was used. Participants had to run 20 meters and step across the line before audio signal (beep). Test started with speed of $8.5 \mathrm{~km} / \mathrm{h}$ which was increased $0.5 \mathrm{~km} / \mathrm{h}$ every minute, until exhaustion [26]. Test was finished when subject could not reach the line two times in a row before the audio signal. All tests were performed outdoor. Measurement equipment used for these tests was stopwatch, photocell (Microgate Witty, Italy), and Beep Test application (Ruval Enterprises). Body height was measured by the portable anthropometer (GPM, Switzerland), while body mass was measured by the bioelectric impedance (InBody720; Biospace Co., Seoul, Korea).

\section{Measurement protocols}

Every participant made six tests, two C, S, and SR tests. Participant first performed the $\mathrm{S}$ test, followed by the $\mathrm{C}$ and SR tests. All tests were made in the morning, and participants performed one test per day and rest until next day. Break between two tests was at least 24 hours. Before performing the tests, participants were required to warm up for a period of approximately 10 minutes (5 minutes of light running and strength exercise - squats and jumps, and 5 minutes of active leg stretching). After the warm up (15 minutes), the electrodes were positioned at the LI position, and the participants sat down for 5 minutes, while the ECG was recording. When the test was finished the participant rested for the next 5 minutes in a sitting position without interrupting the ECG recording [27]. During testing, 5 measurement errors were observed (Bluetooth connection interruption and electrode drop off). These tests were repeated.

\section{E. Statistical analysis}

Descriptive statistics were calculated for all measured variables, and test of normality was made for all the data. For the data which was not distributed normally by the Kolmogorov-Smirnov and the Shapiro-Wilk test results, based on the results of Skewness, transformation with function $\log 10$ or $\log 10$ reflexion was made. For all original and transformed variables that showed normal distribution, for determination of differences the Student t-test for dependent variables was used, while the non-parametric Wilcoxon test was used for those which were not distributed normally. Intraclass correlation was counted for repeated measurements. The significance level was set to $\mathrm{p}<0.05$ [28]. The statistical analysis was conducted using IBM SPSS Statistics 20 software.

\section{RESULTS}

A total of 138 ECG measurements were collected in the duration of about 40 hours. All participants performed all tests as best as they could. Their effort was controlled by time measurements, and intra-class correlation (ICC) was counted for all three tests, which showed that the condition was fulfilled (ICC: $\mathrm{C}-0.901 ; \mathrm{S}-0.894 ; \mathrm{SR}-0.839, \mathrm{p}<0.01$ ). The computerized heart-rate analyses were successful for most of the time during the tests.

Table 1. Descriptive statistics for the Cooper test with Polar belt or tape fixation.

\begin{tabular}{|c|c|c|c|c|c|c|c|c|}
\hline & 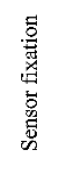 & 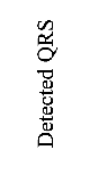 & 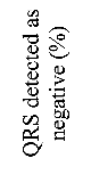 & 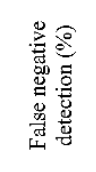 & 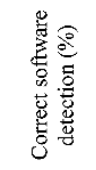 & 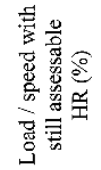 & 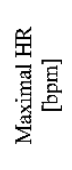 & 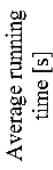 \\
\hline \multirow{3}{*}{$\sum_{\Sigma}^{\sharp \pi}$} & $A \perp L$ & 687.2 & $\begin{array}{c}124.02 \\
(4.99 \%)\end{array}$ & $\begin{array}{c}106.11 \\
(82.47 \%)\end{array}$ & $\begin{array}{c}17.91 \\
(13.18 \%)\end{array}$ & $\begin{array}{c}9.29 \\
(75.33 \%)\end{array}$ & 190.37 & 758 \\
\hline & Polar & 3104.30 & $\begin{array}{l}72.30 \\
(2.14 \%)\end{array}$ & $\begin{array}{c}69.74 \\
(87.81 \%)\end{array}$ & $\begin{array}{c}2.57 \\
(7.84 \%)\end{array}$ & $\begin{array}{l}12.48 \\
(100 \%)\end{array}$ & 190.96 & 768 \\
\hline & Tape & 2270.17 & $\begin{array}{c}175.74 \\
(7.84 \%)\end{array}$ & $\begin{array}{c}142.48 \\
(77.13 \%)\end{array}$ & $\begin{array}{c}33.26 \\
(18.52 \%)\end{array}$ & $\begin{array}{c}6.09 \\
(50.66 \%)\end{array}$ & 189.78 & 743 \\
\hline \multirow{3}{*}{ 烎 } & ALI & 796.75 & $\begin{array}{c}198.20 \\
(7.64 \%)\end{array}$ & $\begin{array}{c}185.24 \\
(27.06 \%)\end{array}$ & $\begin{array}{c}54.06 \\
(20.60 \%)\end{array}$ & $\begin{array}{c}5.31 \\
(40.75 \%)\end{array}$ & 9.33 & 133 \\
\hline & olar & 597.09 & $\begin{array}{c}154.62 \\
(4.03 \%)\end{array}$ & $\begin{array}{c}153.33 \\
(24.42 \%)\end{array}$ & $\begin{array}{c}5.52 \\
(15.26 \%)\end{array}$ & $\begin{array}{c}2.20 \\
(0.00 \%)\end{array}$ & 10.00 & 140 \\
\hline & Tape & 760.44 & $\begin{array}{c}225.50 \\
(9.28 \%)\end{array}$ & $\begin{array}{c}209.56 \\
(29.01 \%)\end{array}$ & $\begin{array}{c}73.86 \\
(23.99 \%)\end{array}$ & $\begin{array}{c}5.62 \\
(46.09 \%)\end{array}$ & 8.79 & 132 \\
\hline
\end{tabular}

Table 2. Descriptive statistics for the $100 \mathrm{~m}$ sprint test with Polar belt or tape fixation.

\begin{tabular}{|c|c|c|c|c|c|c|c|c|}
\hline & 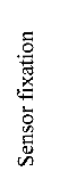 & 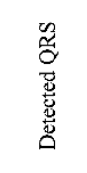 & 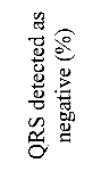 & 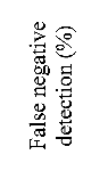 & 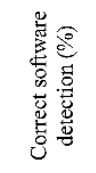 & 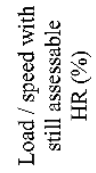 & 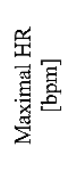 & 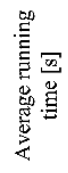 \\
\hline \multirow{3}{*}{$\sum_{\bar{\Sigma}}^{\mathbb{E}}$} & $\Lambda L L$ & 2687.24 & $\begin{array}{c}45.41 \\
(3.27 \%)\end{array}$ & $\begin{array}{c}40.70 \\
(72.50 \%)\end{array}$ & $\begin{array}{c}4.72 \\
(18.80 \%)\end{array}$ & $\begin{array}{c}6.34 \\
(43.48 \%)\end{array}$ & 184.41 & 14.70 \\
\hline & Polar & 3104.30 & $\begin{array}{c}10.22 \\
(0.91 \%)\end{array}$ & $\begin{array}{c}9.52 \\
(74.38 \%)\end{array}$ & $\begin{array}{c}0.70 \\
(12.57 \%)\end{array}$ & $\begin{array}{c}11.40 \\
(78.26 \%)\end{array}$ & 184.52 & 14.76 \\
\hline & Tape & 2270.17 & $\begin{array}{c}80.61 \\
(5.63 \%)\end{array}$ & $\begin{array}{c}71.87 \\
(70.61 \%)\end{array}$ & $\begin{array}{c}8.74 \\
(25.04 \%)\end{array}$ & $\begin{array}{c}1.28 \\
(8.70 \%)\end{array}$ & 184.30 & 14.84 \\
\hline \multirow{3}{*}{ 密 } & ALL & 796.75 & $\begin{array}{c}118.05 \\
(8.04 \%)\end{array}$ & $\begin{array}{c}115.90 \\
(37.93 \%)\end{array}$ & $\begin{array}{c}11.43 \\
(31.01 \%)\end{array}$ & $\begin{array}{c}7.35 \\
(50.12 \%)\end{array}$ & 9.45 & 1.42 \\
\hline & Polar & 597.09 & $\begin{array}{c}27.93 \\
(2.92 \%)\end{array}$ & $\begin{array}{c}27.66 \\
(38.51 \%)\end{array}$ & $\begin{array}{c}1.22 \\
(25.29 \%)\end{array}$ & $\begin{array}{c}6.23 \\
(42.17 \%)\end{array}$ & 8.86 & 1.39 \\
\hline & Tape & 760.44 & $\begin{array}{c}158.54 \\
(10.58 \%)\end{array}$ & $\begin{array}{c}157.09 \\
(38.11 \%)\end{array}$ & $\begin{array}{c}15.62 \\
(35.29 \%)\end{array}$ & $\begin{array}{c}4.26 \\
(28.81 \%)\end{array}$ & 10.20 & 1.39 \\
\hline
\end{tabular}

All observed variables are summarized in Table 1., Table 2. and Table 3., and presented as a mean and standard deviation $( \pm$ SD). Signal quality was high and acceptable in all measured tests with both types of sensor fixation (above $99 \%$ 
of detected QRS on average). However, comparing both types of fixation, all measurements accomplished with Polar belt showed higher quality of ECG signals $(p<0.05)$ for all tests performed (Table 4.). The presented results show the significant difference between variables "detected QRS" for C and SR tests, "QRS detected as negative", "correct software detection", and "load/speed with still assessable HR" for all three tests.

Table 3. Descriptive statistics for the Shuttle run test with Polar belt or tape fixation.

\begin{tabular}{|c|c|c|c|c|c|c|c|c|}
\hline & 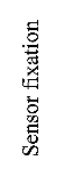 & 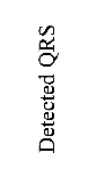 & 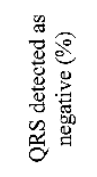 & 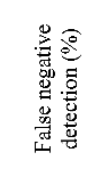 & 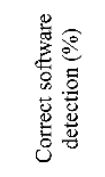 & 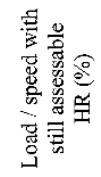 & 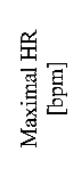 & 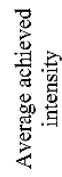 \\
\hline \multirow{3}{*}{$\sum_{\sum}^{\mathbb{3}}$} & ALL & 7 & & & $\begin{array}{r}6 \\
(14\end{array}$ & $\begin{array}{c}8 / 43 \\
(91.23 \%)\end{array}$ & 198.48 & $9 / 44$ \\
\hline & Polar & & $\begin{array}{r}53 . \\
(1.9\end{array}$ & & & & 200.04 & $9 / 27$ \\
\hline & 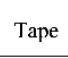 & 2 & & & & $\begin{array}{c}7 / 59 \\
(82.47 \%)\end{array}$ & 91 & 61 \\
\hline \multirow{3}{*}{ 昂 } & & & $\begin{array}{c}154.63 \\
(6.56 \%)\end{array}$ & $\begin{array}{r}152 \\
(24.7\end{array}$ & $\begin{array}{c}11.67 \\
(21.38 \%)\end{array}$ & $\begin{array}{c}2 / 71 \\
(23.57 \%)\end{array}$ & & $1 / 78$ \\
\hline & Dila & 6.43 & $\begin{array}{c}113.45 \\
(4.19 \%)\end{array}$ & $\begin{array}{c}113.50 \\
(29.11 \%)\end{array}$ & $\begin{array}{c}3.31 \\
(23.13 \%)\end{array}$ & $\begin{array}{c}1 / 76 \\
(0.00 \%)\end{array}$ & 7.34 & $18 / 10$ \\
\hline & Tap & 589.62 & $\begin{array}{c}179.07 \\
(7.69 \%)\end{array}$ & $\begin{array}{c}177.29 \\
(19.98 \%)\end{array}$ & $\begin{array}{c}15.33 \\
(19.98 \%)\end{array}$ & $\begin{array}{c}3 / 23 \\
(31.24 \%)\end{array}$ & 7.26 & $1 / 81$ \\
\hline
\end{tabular}

Table 4. Differences between two types of fixation (Polar belt vs. tape fixation).

\begin{tabular}{cccc}
\hline & Cooper 2400 $\mathrm{m}$ & Sprint 100 $\mathrm{m}$ & Shuttle run \\
\hline Detected QRS & $\mathbf{0 . 0 0 0}$ & 0.99 & $\mathbf{0 . 0 0 0}$ \\
QRS detected as negative & $\mathbf{0 . 0 4 9}$ & $\mathbf{0 . 0 0 3}$ & $\mathbf{0 . 0 4 9}$ \\
lalse negative detection & 0.09 & 0.052 & 0.068 \\
Correct software detection & $\mathbf{0 . 0 0 9}$ & $\mathbf{0 . 0 2 4}$ & $\mathbf{0 . 0 0 5}$ \\
I.oad / speed with still assessable HR & $\mathbf{0 . 0 0 0}$ & $\mathbf{0 . 0 0 0}$ & $\mathbf{0 . 0 1 5}$ \\
\hline
\end{tabular}

Legend: All $\mathrm{p}<0.05$ are bolded

\section{DISCUSSION}

This study investigated the possibility of measuring quality electrocardiographic report using an ECG bodysensor during standardized outdoor tests and different types of sensor fixation influence on the quality of the ECG signal during sub-maximal and maximal running settings. To the best of our knowledge, this is the first study that deals with this topic.

The results of our study have confirmed that it is possible to measure quality electrocardiographic report using the ECG body sensor during standardized outdoor tests. Also, fixation with Polar belt is more adequate for measurements made during physical activity in real setting than fixation with standard ECG electrodes with tape fixation, because sensor contact stays tight during the whole activity, while electrodes and fixation strip can peel off due to increased perspiration, and due to the increased forces which act on the body during running.

The most common mistakes in QRS detection appeared during maximal running velocities. By visual examination of the ECG data we detected the presence of motion artefacts, especially when subjects were participating in maximal (allout) tests. High velocity and force which acts on the body during maximal running speed produces motion artefacts in the ECG signal [22], which made the signal unusable. These artefacts were more pronounced in tests with tape fixation, in comparison to tests with Polar belt. Also, movements without acceleration can have a marked influence on the ECG signal. In 5 cases the connection was broken. In three cases several times during monitoring Bluetooth connection was lost for a few seconds, while in two cases one electrode dropped off close to the end of the test. During the visual inspection we also found erroneously detected QRS complexes by using the Holter interpretation software.

We have demonstrated that in all tests with moderate or severe intensity ECG signal was acceptable at the level above $99 \%$ on average. It should be noted that after completion of physical activity in all cases the quality of the recorded ECG signal was adequate for the interpretation, and all participants in the study had normal ECG findings. This is especially important because previous studies confirmed that sudden cardiac events happened during physical activity or within an hour after cessation of activity [29].

Unfortunately, we could not find previous studies, beside one case study of Širaiy \& Trobec [19], dealing with quality of signals obtained with telemetric ECG sensors in field trials. However, few studies made in laboratory conditions, using different telemetric ECG sensors in different laboratory tests, confirmed that level of activity and type of sensors' fixation influence the final quality of the ECG signal. Two previous studies [30], [31] reported that the ECG signal was of adequate quality during resting, walking, or jogging, but some motion artefacts were present during running or jumping activities. Takalokastari and co-workers [32] found that the ECG signal during running on the treadmill was of moderate or good quality, and acceptable at the level of $60 \%$, while during the Nordic walking test signal was acceptable at the level of $79 \%$. The main conclusion of the study was that special attention should be paid to improve the quality of the signal.

Sensor from the present study was previously used during EST in laboratory conditions with the same type of fixation and used electrodes [18]. The additional fixation of the sensor with self-adhesive tapes at position LI showed improvement of the signal quality on the treadmill up to the level of $97.64 \%$, while on a cycle ergometer the signal was acceptable at the $100 \%$ level. This leads to the conclusion that real settings influence the quality of the ECG signal even more because disturbing factors are stronger than in the laboratory, and sensor must be fixed in a different way to provide the high-quality signal.

Standard 12-lead ECG is a golden standard for detecting arrhythmias and myocardial ischemia or infarction [33]. However, with wireless technological advances, ECG body sensors have evolved to satisfy contemporary needs [34]. These devices are unobtrusive for users and allow long-term monitoring which improves the diagnostic capability [20]. The ECG body sensor presented in this study was already tested in a previous study on cardiac patients [35], and the quality of the ECG signal had been compared with other similar devices [21], and with standard 12-lead ECG [21], [36]. It was confirmed that this body sensor can detect most of the arrhythmic events, e.g., atrial or ventricular fibrillation, 
extrasystole, tachycardias, bradycardias, VES, SVES, etc. [20]. However, a single-channel device has serious limitations in detection of exercise-induced ischemia, e.g., it is not possible to accurately assess ST deviations during stress testing procedures.

Based on the foregoing, wireless ECG body sensor could be very beneficial in early detection of cardiac conduction abnormalities. Also, such portable systems could be supportive during kinesiotherapy and rehabilitation process in patients with a high risk of cardiac arrest during physical exertion, e.g., coronary heart disease, chronic obstructive lung disease, gait disabilities, or amputees [4], [20], [37]. Furthermore, it could be highly applicable in various physical activities and sports as a diagnostic tool, mainly for preparticipation screening and prevention of sports-related sudden cardiac death.

\section{CONCLUSION}

This study showed that wireless ECG body sensor could be a useful medical device for cardiac rhythm monitoring during physical activity in real settings. Even though one-channel ECG sensor provides less information than a standard 12-lead ECG, it can still provide important information about heart rhythm during exercise. Properly fixed with Polar belt, this sensor is very reliable in the sub-maximal and maximal field tests. ECG body sensor allows the users long-term monitoring of heart function, and easy generation of the reports which can be sent to a medical doctor. Consequently, it could be very beneficial for medical doctors, and potentially might help in early detection of cardiac conduction abnormalities during rest or exercise in patients, recreational and professional athletes. In this study we have chosen a small, homogeneous group of healthy young participants, hence in order to verify these claims future larger population studies should include participants in other age groups with focus on middle-age and patients with irregular cardiac rhythm.

\section{ACKNOWLEDGEMENT}

The paper is a part of the projects III47015 and 41022 , funded by the Ministry of Education, Science and Technological Development of the Republic of Serbia.

\section{REFERENCES}

[1] Arnett, D.K., Blumenthal, R.S., Albert, M.A. et al. (2019). 2019 ACC/AHA guideline on the primary prevention of cardiovascular disease: A report of the American College of Cardiology/American Heart Association Task Force on Clinical Practice Guidelines. Journal of the American College of Cardiology, 74 (10), e177-e232.

[2] Hajar, R. (2017). Risk factors for coronary artery disease: Historical perspectives. Heart Views, 18 (3), 109-114.

[3] Maron, B.J. (2003). Sudden death in young athletes. New England Journal of Medicine, 349 (11), 10641075.
[4] Thompson, P.D., Franklin, B.A., Balady, G.J. et al. (2007). Exercise and acute cardiovascular events placing the risks into perspective: A scientific statement from the American Heart Association Council on Nutrition, Physical Activity, and Metabolism and the Council on Clinical Cardiology. Circulation, 115 (17), 2358-2368.

[5] Mazić, S., Ilić, V., Djelić, M., Arandjelović, A. (2011). Sudden cardiac death in young athletes. Srpski Arhiv za Celokupno Lekarstvo, 139 (5-6), 394-401.

[6] Chevalier, L., Hajjar, M., Douard, H., Cherief, A., Dindard, J.M., Sedze, F., Ricard, R., Vincent, M.-P., Corneloup, P. Gencel, L., Carre, F. (2009). Sportsrelated acute cardiovascular events in a general population: A French prospective study. European Journal of Cardiovascular Prevention \& Rehabilitation, 16 (3), 365-370.

[7] Marijon, E., Uy-Evanado, A., Reinier, K., Teodorescu, C., Narayanan, K., Jouven, X., Gunson, K., Jui, J., Chugh, S.S. (2015). Sudden cardiac arrest during sports activity in middle age. Circulation, 131 (16), 13841391.

[8] Gräni, C., Chappex, N., Fracasso, T., Vital, C., Kellerhals, C., Schmied, C., Saguner, A.M., Trachsel, L.D., Eser, P., Michaud, K., Wilhelm, M. (2016). Sports-related sudden cardiac death in Switzerland classified by static and dynamic components of exercise. European Journal of Preventive Cardiology, 23 (11), 1228-1236.

[9] Marijon, E., Tafflet, M., Celermajer, D.S., Dumas, F., Perier, M.C., Mustafic, H., Toussaint, J.-F., Desnos, M., Rieu, M., Benameur, N., Le Heuzey, J.-Y., Empana, J.P., Jouven, X. (2011). Sports-related sudden death in the general population. Circulation, 124 (6), 672-681.

[10] Berdowski, J., de Beus, M.F., Blom, M., Bardai, A., Bots, M.L., Doevendans, P.A., Grobbee, D.E., Tan, H.L., Tijssen, J.G.P., Koster, R.W., Mosterd, A. (2013). Exercise-related out-of-hospital cardiac arrest in the general population: Incidence and prognosis. European Heart Journal, 34 (47), 3616-3623.

[11] Goodman, J.M., Burr, J.F., Banks, L., Thomas, S.G. (2016). The acute risks of exercise in apparently healthy adults and relevance for prevention of cardiovascular events. Canadian Journal of Cardiology, 32 (4), 523532.

[12] Rumboldt, M., Kuzmanić, M., Petrić, D., Rumboldt, Z. (2011). Unsatisfactory cardiovascular risk controlopportunities for family medicine. Slovenian Journal of Public Health, 50 (1), 75-81.

[13] Banerjee, A., Newman, D.R., Van den Bruel, A., Heneghan, C. (2012). Diagnostic accuracy of exercise stress testing for coronary artery disease: A systematic review and meta-analysis of prospective studies. International Journal of Clinical Practice, 66 (5), 477492.

[14] Sharif, S.E., Alway, S. (2016). The diagnostic value of exercise stress testing for cardiovascular disease is more than just st segment changes: A review. Journal of Integrative Cardiology, 2 (4), 41-55. 
[15] Chou, R., Arora, B., Dana, T., Fu, R., Walker, M., Humphrey, L. (2011). Screening asymptomatic adults with resting or exercise electrocardiography: A review of the evidence for the US Preventive Services Task Force. Annals of Internal Medicine, 155 (6), 375-385.

[16] Stern, S., Tzivoni, D. (1974). Early detection of silent ischaemic heart disease by 24-hour electrocardiographic monitoring of active subjects. British Heart Journal, 36 (5), 481-486.

[17] Lumikari, T.J., Putaala, J., Kerola, A., Sibolt, G., Pirinen, J., Pakarinen, S., Lehto, M., Nieminen, T. (2019). Continuous 4-week ECG monitoring with adhesive electrodes reveals AF in patients with recent embolic stroke of undetermined source. Annals of Noninvasive Electrocardiology, 24 (5), e12649.

[18] Širaiy, B., Trobec, R., Ilić, V. (2019). Quality of onechannel telemetric ECG sensors signal in maximum exercise stress tests. Measurement Science Review, 19 (3), 79-85.

[19] Šriaiy B, Trobec R. (2019). Telemetric ECG monitoring during physical activity in field tests. Electronic Devices, 8 (1), 1-6.

[20] Rashkovska, A., Depolli, M., Tomašić, I., Avbelj, V., Trobec, R. (2020). Medical-grade ECG sensor for longterm monitoring. Sensors, 20 (6), 1695.

[21] Trobec, R., Tomašić, I., Rashkovska, A., Depolli, M., Avbelj, V. (2018). Body Sensors and Electrocardiography. Springer, ISBN 978-3-31959338-8.

[22] Clancy, E.A., Morin, E.L., Merletti, R. (2002). Sampling, noise-reduction and amplitude estimation issues in surface electromyography. Journal of Electromyography and Kinesiology, 12 (1), 1-16.

[23] Puurtinen, M., Viik, J., Hyttinen, J. (2009). Best electrode locations for a small bipolar ECG device: Signal strength analysis of clinical data. Annals of Biomedical Engineering, 37 (2), 331-336.

[24] Kania, M., Rix, H., Fereniec, M., Zavala-Fernandez, H., Janusek, D., Mroczka, T., Stix, G., Maniewski, R. (2014). The effect of precordial lead displacement on ECG morphology. Medical \& Biological Engineering \& Computing, 52 (2), 109-119.

[25] Auersperger, I., Knap, B., Jerin, A., Blagus, R., Lainscak, M., Skitek, M., Skof, B. (2012). The effects of 8 weeks of endurance running on hepcidin concentrations, inflammatory parameters, and iron status in female runners. International Journal of Sport Nutrition and Exercise Metabolism, 22 (1), 55-63.

[26] Leger, L.A., Mercier, D., Gadoury, C., Lambert, J. (1988). The multistage 20 metre shuttle run test for aerobic fitness. Journal of Sports Sciences, 6 (2), 93101.

[27] Sbrollini, A., Morettini, M., Maranesi, E., Marcantoni, I., Nasim, A., Bevilacqua, R., Riccardi, G.R., Burattini, L. (2019). Sport Database: Cardiorespiratory data acquired through wearable sensors while practicing sports. Data in Brief, 27, 104793.
[28] Hair, J.F., Black, W.C., Babin, B.J., Anderson, R.E. (2010). Multivariate Data Analysis. Pearson, 7th edition, ISBN 978-0138132637.

[29] Harmon, K.G., Asif, I.M., Klossner, D., Drezner, J.A. (2011). Incidence of sudden cardiac death in national collegiate athletic association athletes. Circulation, 123 (15), 1594-1600.

[30] Shen, C.L., Kao, T., Huang, C.T., Lee, J.H. (2007). Wearable band using a fabric-based sensor for exercise ecg monitoring. In 10th IEEE International Symposium on Wearable Computers, 11-14 October 2006. IEEE, 143-144.

[31] Valchinov, E., Antoniou, A., Rotas, K., Pallikarakis, N. (2015). Wearable ECG system for health and sports monitoring. In 4th International Conference on Wireless Mobile Communication and Healthcare Transforming Healthcare Through Innovations in Mobile and Wireless Technologies (MOBIHEALTH), 35 November 2014. IEEE, 63-66.

[32] Takalokastari, T., Alasaarela, E., Kinnunen, M., Jämsä, T. (2014). Quality of the wireless electrocardiogram signal during physical exercise in different age groups. IEEE Journal of Biomedical and Health Informatics, 18 (3), 1058-1064.

[33] Fletcher, G.F., Ades, P.A., Kligfield, P., Arena, R., Balady, G.J., Bittner, V.A., Coke, L.A., Fleg, J.L., Forman, D.E., Gerber, T.C., Gulati, M., Madan, K., Rhodes, J., Thompson, P.D., Williams, M.A. (2013). Exercise standards for testing and training: A scientific statement from the American Heart Association. Circulation, 128 (8), 873-934.

[34] Fung, E., Järvelin, M.R., Doshi, R.N., Shinbane, J.S., Carlson, S.K., Grazette, L.P., Chang, P.M., Sangha, R.S., Huikuri, H.V., Peters, N.S. (2015). Electrocardiographic patch devices and contemporary wireless cardiac monitoring. Frontiers in Physiology, 6, 149.

[35] Jan, M., Trobec, R. (2017). Long-term follow-up case study of atrial fibrillation after treatment. In 40th International Convention on Information and Communication Technology, Electronics and Microelectronics (MIPRO), 22-26 May 2017. IEEE, 297-302.

[36] Trobec, R., Avbelj, V., Rashkovska, A. (2014). Multifunctionality of wireless body sensors. The IPSI BgD Transactions on Internet Research, 10 (1), 23-27.

[37] Petrini, F.M., Bumbasirevic, M., Valle, G. et al. (2019). Sensory feedback restoration in leg amputees improves walking speed, metabolic cost and phantom pain. Nature Medicine, 25 (9), 1356-1363.

Received March 20, 2021

Accepted May 07, 2021 